FEATURED CASE REPORT

\title{
Pacing extremely old patients: who decides - the doctor, the patient, or the relatives?
}

\author{
G M Sayers, H W L Bethell
}

Heart 2004;90:134-135. doi: 10.1136/hrt.2003.022731

Decision making competence is not necessarily present or absent. In many cases it is partial or compromised. This applies especially to those over 80 years old, in whom the prevalence of dementia is high. Three patients who presented with indications for permanent pacemaker insertion are considered. One was apparently competent, one had partial competence, and one was clearly incompetent. In all three cases the closest relatives were opposed to decisions made by either the patient or the doctors. The three cases reflect the tension between doctors, patients, and relatives in situations where medical interests, individual interests, and familial interests conflict. The cases illustrate the type of problems encountered in clinical practice. The current legal position is reviewed.

D ecision making competence is not necessarily present or absent. In many cases it is partial or compromised. This applies especially to those over 80 years old, in whom the prevalence of dementia is high. Increasing age often leads to vulnerability and family members understandably become concerned and protective.

Three patients who presented with indications for permanent pacemaker insertion are considered. One was apparently competent, one had partial competence, and one was clearly incompetent. In all three cases the closest relatives were opposed to decisions made by either the patient or the doctors.

Current English law does not permit proxy consent for an adult incapable of decision making. Instead, the doctor is authorised to act in the patient's best interests. Such interests are broadly defined in law, yet doctors are largely trained, and hence inclined, to assess medical interests.

In accordance with the law, one patient was paced with her consent, one was not paced because of her apparent wishes, and the third patient, unable to express a preference, was paced in her apparent best interests.

The three cases reflect the tension between doctors, patients, and relatives in situations where medical interests, individual interests, and familial interests conflict. The cases are presented in abstract form, as they are intended simply to illustrate the type of problems encountered in clinical practice. The discussion that follows focuses on the current legal position.

\section{CASE 1}

This 101 year old patient was admitted after a fall that she did not recall. The ECG showed trifascicular block and pacemaker insertion was planned. The patient was physically frail but competent, her abbreviated mental test score being 9 of 10. She understood what pacing entailed and why it was proposed. She asked to meet a patient fitted with a pacemaker and after speaking to him decided to accept the intervention.

Her next of kin stated he was totally opposed to the operation-"a pacemaker at her age of 101 ". He elaborated: "She herself does not want the operation. It would be easy to get her to sign a consent form but this would not be valid, as she is not able to fully understand at her age." He insisted she be discharged immediately.

The relative was told that the patient was competent to consent, that pacing was medically indicated, and although it carried a small risk, without pacing the risk was greater. Although the relative remained unconvinced, the patient was successfully paced and discharged home.

\section{CASE 2}

An 87 year old woman collapsed with no recollection of the event. The ECG showed a Mobitz type II block with bradycardia. Although the family agreed with pacing, the patient refused the procedure. She was cognitively impaired with a mental test score of 6 of 10 . She understood and recalled the explanations given by her doctors but repeatedly refused the intervention on the basis that she did not want an operation. This refusal was respected and she died one month later.

\section{CASE 3}

This 90 year old patient with Alzheimer's disease was admitted with complete heart block complicated by heart failure. She lived alone with carer support. Her abbreviated mental test score was 3 of 10. Although orientated for person and place, she was unable to understand the proposed procedure or recall previous explanations. After admission she experienced two brief episodes of cardiac syncope with spontaneous recovery.

The relatives disagreed with pacemaker insertion. They felt her quality of life was too poor and were afraid of distressing her. Doctors explained that sedation and reassurance would be provided, and that further syncope could cause more trauma than the procedure. After lengthy discussions they reluctantly assented to pacing, which was successfully performed.

\section{DISCUSSION}

The primacy of autonomy, with its corollary self determination, allows those who are competent to decide the right to decide for themselves. Legally, and expressed in the words of Judge Cardozo, "Every human being of adult years and sound mind has a right to determine what shall be done with his own body; and a surgeon who performs an operation without his patient's consent commits an assault ...."'

Disputing that a competent patient should have the right to decide what happens to his or her own body is unjustifiable. This applies to the relative described in case 1. Even when people decide (apparently) contrary to their best interests, as in case 2, few would deny them the 
opportunity to do so. This is recognised by law. In the UK a person has a right to choose whether to consent to treatment, "whether the reasons for making that choice are rational, irrational, unknown or even non-existent". ${ }^{2}$

In attesting to decision making competency, common law requires the presence of three abilities. These are the ability to comprehend and retain treatment information; to believe it; and to balance it in order to make a choice. ${ }^{3}$

These components of choice were all present in the second patient, although the reason for her decision may appear irrational.

The Law Commission also favours a functional definition of incompetence, describing it as the inability to decide, ${ }^{4}$ the inability to understand or use information, ${ }^{5}$ or the inability to communicate a decision. ${ }^{6}$

People with parental responsibility are legally permitted to consent to treatment for children not yet competent to decide. $^{7}$ In the case of incompetent adults, however, "the next of kin...has no legal right to consent or to refuse consent to medical treatment on behalf of the patient". ${ }^{8}$ Instead, the doctor is authorised to act in the best interests of the patient on the basis of necessity. ${ }^{\text {" }}$

The "best interests" assessment, itself a value judgement, is often open to interpretation. There is a fundamental presumption that continuing life and improved health are valuable, but this does not address the issues raised by severe dementia. In such cases it is hard to ignore the patient's quality of life when weighing the risks and benefits of many proposed treatments.

When considering the risks and benefits of pacing the third patient, emphasis was placed on the risk of further episodes of collapse with concomitant injury and the risk of sudden death. These interests are largely medical. Broader interests include the cost of pacing, balanced against the cost of further admissions, as well as the relatives' interests and perspective.

Quality of life evaluation is often subjective. The third patient's relatives were opposed to life prolonging measures partly on this account. The courts heed relatives' views, especially those regarding what the patient would have chosen had she been competent.

This process of substituted judgement theoretically enables decision making congruent with the patient's previous values and preferences. The obvious difficulty is that few people discuss medical procedures. Hence, predicting what they would have chosen, were they able, is often inaccurate and may be meaningless. ${ }^{10}$

As many best interests judgements are value laden and indeterminate, there are good moral arguments supporting relatives rather than doctors in making these decisions. Relatives know the patient with dementia and many decisions are family based. ${ }^{11}$ Even when relatives appear to make non-patient based decisions, it is submitted that such decisions be accorded sympathetic hearing. ${ }^{12}$

Nevertheless, in England the relatives' opinions remain informative rather than determinative. It may be argued that depriving relatives of decision making capacity in matters concerning their close family members violates Article 8 of the Human Rights Act 1998, although this has not been challenged by the courts. ${ }^{13}$

In Scotland, the Adults with Incapacity (Scotland) Act 2000 enables appointment of a guardian or a welfare attorney with power in relation to the medical treatment of an incompetent patient. ${ }^{14}$ But English law relating to mental incapacity has been described by the Law Commission as: "...unsystematic and full of glaring gaps. It does not rest on clear or modern foundations of principle. It has failed to keep up with social and demographic changes." ${ }^{15}$

The Law Commission's proposals for reform, if enacted, will allow the appointment of proxies with legal power to consent on behalf of incompetent adults, provided such decisions are in the best interests of those adults. ${ }^{16}$

\section{Conclusion}

The decision to pace extremely old patients is sometimes met with family opposition. Relatives seeking to reverse decisions made by competent elderly patients are not legally or morally entitled to do so.

If patients with moderate dementia are opposed to intervention, their views should be accorded weight, particularly as the reasons for decision making by competent patients do not have to be rational. Provided that patients broadly understand what is proposed and retain the information given, their decisions should be respected.

Relatives who strive to protect patients with severe dementia from procedures they consider harmful or pointless can often be persuaded by sensitive communication as shown in case 3. But whether this is what ought to be done is debatable.

Reform in this area of English law is expected. Then the relatives' reasonable preferences regarding the treatment of patients with dementia will have legal authority and clinical decision making should be facilitated.

\section{Authors' affiliations}

G M Sayers, Department of Geriatric and General Medicine, Northwick Park Hospital, Harrow, UK

H W L Bethell, Department of Cardiology, Northwick Park Hospital

Correspondence to: Dr G M Sayers, Department of Geriatric and General Medicine, Northwick Park Hospital, Watford Road, Harrow HA1 3UJ; gwen.sayers@imperial.ac.uk

Accepted 4 August 2003

\section{REFERENCES}

1 Schloendorff $v$ Society of New York Hospital [1914] 211 NT per Cardozo J at p: 129-30.

$2 \operatorname{Re} T$ (adult: refusal of medical treatment) [1992] 4 All ER per Lord Donaldson 662a.

3 Re C (adult: refusal of treatment) [1994] 1 WLR 295C.

4 Law Commission. Mental incapacity. London: HMSO, 1995:37, paragraph 3.15 .

5 Law Commission. Mental incapacity. London: HMSO, 1995:38, paragraphs 3.16, 3.17.

6 Law Commission. Mental incapacity. London: HMSO, 1995:40, paragraph 3.20 .

7 Children Act 1989.

8 Re T (adult: refusal of medical treatment) [1992] 4 All ER per Lord Donaldson $650 \mathrm{~b}-\mathrm{c}$.

9 In re F (mental patient: sterilisation) [1989] 2 WLR 1025.

10 Sayers GM, Beckett N, Waters $H$, et al. Surrogate CPR decision-making and the fallacy of substituted judgement. J Clin Ethics, (in press).

11 Brock DW. What is the moral authority of family members to act as surrogates for incompetent patients? Milbank Q 1996;74:599-618.

12 Hardwig J. The problem of proxies with interests of their own: toward a better theory of proxy decisions. In: Is there a duty to die? And other essays in medical ethics. New York: Routledge, 2000:45-60.

13 Human Rights Act 1998. Article 8. Right to respect for private and family life.

14 Adults with Incapacity (Scotland) Act 2000 s50(1).

15 Law Commission. Mental incapacity. London: HMSO, 1995:1, paragraph 1.1.

16 Law Commission. Mental incapacity. London: HMSO, 1995:223, draft Mental Incapacity Bill s3(1). 